\title{
O papel de um centro de P\&D em empresas de ramos tradicionais: o caso da UN de logística da Vale
}

\author{
The role of $R \& D$ centers in traditional companies: the case of the Vale logistics unit
}

Claudio Pitassi ${ }^{1}$

\begin{abstract}
Resumo
Na medida em que o impacto do uso de ciência e tecnologia (C\&T) em produtos e processos de quase todos os ramos de negócio se intensifica, cresce a preocupação das empresas com a criatividade, tempestividade e eficiência das suas estruturas de gestão de P\&D. O objetivo deste artigo é contribuir para o campo de estudo de gestão de C\&T, relatando a evolução do processo de implantação de um modelo de gestão de tecnologia na unidade de negócios (UN) de Logística da Vale, particularmente os fundamentos da proposta de criação de uma estrutura virtual de gestão de tecnologia na UN. O estudo também discute como os fatos ocorridos na Vale entre os anos de 2006 e 2008 repercutiram na decisão de criação de um Centro Tecnológico na mineradora. A metodologia adotada foi o estudo de caso, combinando-a com a de pesquisa-ação. Os dados foram coletados a partir da observação participante do pesquisador durante os dois anos de construção do modelo de gestão de tecnologia, bem como de entrevistas realizadas em visitas de benchmark a empresas atuantes no Brasil e consideradas referência em gestão de P\&D. $O$ Referencial teórico reflete a literatura científica a respeito de gestão estratégica C\&T, com destaque para novas estruturas de promoção da inovação tecnológica no âmbito das empresas privadas. Dentre os resultados obtidos destacam-se: a preferência dos gestores e especialistas da UN por uma estrutura aberta de gestão de P\&D apoiada na rede de alianças com universidades, institutos de pesquisa e, principalmente fornecedores estratégicos; a opção por manter as atividades de desenvolvimento e engenharia nas áreas operacionais da Logística ao invés de centralizá-las em uma área corporativa de gestão estratégica de C\&T.
\end{abstract}

Palavras-chave: inovação; P\&D; centro de tecnologia; estruturas virtuais; parcerias tecnológicas.

\section{Abstract}

As the impact of the use of science and technology (S\&T) on products and processes in almost all business sectors intensifies, firms' concern with the creativity, agility and efficiency of their R\&D structures increases. This article's objective is to contribute to the S\&T management field of study by describing the evolution of the process of implementation of a technology management model in Vale Logistics business unit (BU), particularly the fundamentals behind the proposal of creating a virtual structure to manage technology in the BU. The study also discusses evens that took place at Vale between 2006 and 2008 and which influenced the adoption of a centralized R\&D structure at the company. The methodology adopted is the case study, combined with action research. The data were collected during

Artigo submetido em março de 2009 e aceito para publicação em março de 2010.

1 Doutor em Administração de Empresas pelo IAG da Pontifícia Universidade Católica do Rio de Janeiro; Professor adjunto do Mestrado em Administração da Estácio de Sá (MADE). Endereço: UNESA/MADE - Mestrado em Administração e Desenvolvimento Empresarial, Av. Presidente Vargas 642, 22 andar, CEP 20071-001, Rio de Janeiro, RJ, Brasil. E-mail: claudio.pitassi@gmail.com 
the researcher's participant observation during the two years of the model implementation, as well as from the interviews conducted in benchmark visits to firms doing business in Brazil that were considered references in R\&D management. The theoretical reference framework reflects the scientific literature of strategic S\&T management, emphasizing new structures to promote innovation technology within private enterprises. Among the main results obtained in the case are: the preference of executives and specialists for an open innovation structure to manage R\&D, supported by a network of alliances with universities, research institutes and, mainly, strategic suppliers; and the option to maintain development and engineering activities inside logistics operational areas instead of a centralized corporate unit.

Keywords: innovation; R\&D; technology center; virtual structures; technological alliances.

\section{Introdução}

A questão da inovação tecnológica está ocupando um espaço cada vez maior na agenda das empresas ao redor do mundo. É voz corrente entre pesquisadores a importância deste tema para a sobrevivência das empresas contemporâneas (FREEMAN e SOETE, 1997; NELSON e WINTER, 1977; TIDD, BESSANT e PAVITT, 2005). No Brasil, as políticas de inovação vêm ganhando ênfase desde meados dos anos 1990. Sobressaem também as crescentes preocupações dos empresários brasileiros com a questão da inovação tecnológica e a competitividade das empresas do país (ARRUDA, VELMUM, HOLLANDA, 2006). Apesar dos avanços descritos acima, constata-se que o Sistema Nacional de Inovação (SNI) (LUNDVALL, 1992) brasileiro ainda apresenta sérias fragilidades. Entre as barreiras que o SNI impõe à inovação tecnológica no país, destacam-se: i) a baixa presença ou passividade das empresas privadas na geração ou busca de inovações tecnológicas; ii) o distanciamento ainda existente, no que tange as atividades de P\&D, entre a universidade e as organizações produtivas; iii) a falta de uma ação mais firme do governo como indutor do desenvolvimento de capacitações tecnológicas que permitam ao Brasil superar o atraso e posicionar-se como nação desenvolvida (BRITO CRUZ, 2005; MATIAS-PEREIRA e KRUGLIANSKAS, 2005; SBRAGIA e STAL, 2004).

No sentido contrário do que ocorre no Brasil, a experiência de sucesso da Coreia do Sul, apenas para ficar neste exemplo, demonstra a relevância da organização produtiva privada nas atividades de $\mathrm{P} \& \mathrm{D}$, a ênfase dada à educação de cunho tecnológico e o papel estimulador do estado (BRITO CRUZ, 2005). Especificamente em relação à P\&D nas empresas coreanas, observa-se que a grande maioria das inovações tecnológicas, particularmente aquelas classificadas como incrementais, nascem das reais necessidades do setor produtivo, cujo desempenho é visto como decisivo para que este país destaque-se no cenário mundial como gerador de inovação e de tecnologia (MARTIN e TORKOMIAN, 2001). Mesmo com todas as limitações descritas acima, parte-se do pressuposto neste artigo que as empresas brasileiras devem fazer a parte que lhes cabe, definindo e implantando um modelo de gestão de P\&D que apoie a consecução de suas estratégias empresariais. Esse modelo deve ser capaz de suportar: i) o alinhamento permanente das inovações tecnológicas às estratégias do negócio; ii) a definição clara do posicionamento tecnológico; ii) o acompanhamento do desempenho das estratégias tecnológicas; iii) a gestão das parcerias dedicadas ao processo de inovação tecnológica; iv) o desenvolvimento das capacitações tecnológicas necessárias; v) a definição de uma estrutura de gestão que operacionalize esse modelo.

Em relação ao último item, observa-se uma crescente preocupação nas empresas com a criatividade, tempestividade e eficácia das suas estruturas de gestão de P\&D na medida em que o impacto do uso de ciência e tecnologia (C\&T) em produtos e processos de quase todos os ramos de negócio se intensifica. Surge então o objetivo deste artigo: contribuir para o campo de estudo de gestão de C\&T nas empresas relatando a evolução do processo de implantação de um modelo de gestão de tecnologia na unidade de negócios (UN) de Logística da Vale, particularmente a proposta de criação de uma estrutura virtual de gestão de tecnologia na UN. Aqui, dar-se-á destaque a alguns fatos ocorridos na Vale entre 2006 e 2008 que influenciaram os rumos da criação de um Centro de Tecnologia na empresa, do qual faria parte a estrutura proposta pela Logística. Na perspectiva deste artigo, entende-se por ramos tradicionais aqueles nos quais as trajetórias tecnológicas já estão maduras, a taxa de mudança tecnológica é baixa e, por conseguinte, o ciclo 
de vida do produto é longo. Ainda assim, estes ramos também são fortemente impactados pela inovação tecnológica dos fornecedores de máquinas, equipamentos e tecnologias de automação industrial utilizados nos seus processos produtivos (CASSIOLATO, 1999; FREEMAN e SOETE, 1997; TEECE et al., 1997).

\section{Metodologia}

Esta pesquisa foi conduzida por membros da Gerência Geral (GG) responsável pela elaboração da proposta de um modelo de gestão de tecnologia da UN de Logística da Vale. Ela retrata a evolução deste modelo, cuja primeira fase pode ser vista em PITASSI e BARROS (2005). Por conseguinte, nesta etapa da pesquisa também se adotou a metodologia de estudo de caso (YIN, 1994), combinando-a com a de pesquisa-ação (CHECKLAND, 1991). O estudo de caso, na medida em que considera as dimensões de tempo e espaço, mostrou-se uma ferramenta metodológica adequada à análise de um fenômeno cuja evolução se dava concomitantemente às profundas mudanças estruturais que ocorriam na Vale nos anos de implantação deste modelo e cujo controle por parte do pesquisador era impossível, inviabilizando uma análise retrospectiva (YIN, 1994). A observação participante foi vista como uma fonte indispensável e intrinsecamente ligada ao processo de uma pesquisa-ação, na qual o investigador tem a capacidade de atuar no ambiente estudado e interferir nos resultados. É importante ressaltar que ocorreram profundas alterações de estrutura na Vale em geral - e na Logística em particular - posteriormente à realização da pesquisa aqui retratada, particularmente em decorrência da aquisição da INCO e do spin-off da Log-in. Ainda assim, acredita-se que estes fatos, os quais serão descritos com mais detalhes à frente, não comprometem o objetivo pretendido neste artigo. Cumpre ressaltar também que a relação entre os centros de P\&D das UNs e o Centro de Tecnologia da Vale era um dos pontos centrais da proposta de modelo de gestão em discussão na empresa.

O referencial teórico, selecionado a partir da pesquisa bibliográfica, trouxe aspectos de gestão de C\&T que se revelaram importantes para subsidiar as discussões voltadas à complementação do modelo de gestão tecnologia da Vale Logística. A coleta de dados no campo ocorreu em duas frentes. Ao longo do primeiro semestre de 2006, integrantes da GG supracitada visitaram empresas atuantes no Brasil consideradas referência em gestão de P\&D. Aceitaram participar da pesquisa, as seguintes empresas: Embraco, Embraer, Petrobrás (Cenpes), Siemens, ALL logística, Natura, WEG, Cemig e Braskem. As evidências foram coletadas em entrevistas com o executivo principal e consultores internos da área de P\&D de cada uma destas empresas. As entrevistas foram apoiadas em um roteiro pré-estabelecido, por meio do qual se buscou coletar evidências que permitissem correlacionar dimensões consideradas críticas para a definição da futura estrutura do centro de P\&D da Vale Logística. Entre os aspectos discutidos, estavam tópicos como tamanho da empresa, ramo de atuação, taxa de mudança tecnológica, posicionamento tecnológico, estruturas de P\&D utilizadas, parcerias estratégicas em C\&T, etc. A consolidação destes dados, omitidos por solicitação das empresas, gerou uma tabela de referência utilizada para subsidiar as discussões internas, realizadas ao longo do segundo semestre de 2005 e do primeiro semestre de 2006. Neste período, representantes da GG que haviam feito as visitas de benchmark reuniram-se com 48 executivos e especialistas em tecnologia envolvidos na gestão de $\mathrm{P} \& \mathrm{D}$ na Vale Logística. Participaram das discussões as áreas de planejamento estratégico, PCP, engenharia, automação industrial e manutenção de vagões e locomotivas. As opiniões coletadas nestes encontros eram apresentadas em datas pré-estabelecidas nas reuniões de acompanhamento com as Diretorias de Planejamento e Operações. De acordo com a dinâmica de uma pesquisa--ação, o modelo de gestão foi sendo interativamente ajustado na medida em que novos insights eram obtidos no confronto entre as evidências coletadas na revisão da literatura e aquelas observadas no campo, inclusive nas visitas de benchmark. 
Referencial Teórico

\section{Economia do Conhecimento, Inovação Tecnológica e Estratégia Empresarial}

A difusão das tecnologias de informação e comunicação (TICs) e o rápido desenvolvimento nas últimas décadas da biotecnologia, das ciências da cognição e da nanotecnologia geraram um processo de convergência tecnológica cujos impactos sociais e econômicos estão absolutamente indefinidos (CASSIOLATO, 1999). Dois efeitos simultâneos decorrem deste contexto: i) a emergência de novos ramos que transformam em negócio as tecnologias emergentes, cuja característica principal é o ciclo curto de vida do produto (DAY e SCHOEMAKER, 2000); ii) a revitalização de ramos tradicionais acarretada pelas inovações incrementais embutidas em máquinas e equipamentos produzidos por fornecedores inovadores (MUNIZ, 2000). Os efeitos conjugados destes fenômenos aumentaram exponencialmente a complexidade, a taxa de mudança tecnológica e as incertezas do ambiente de negócios. Para CASSIOLATO (1999), "as mudanças baseadas nas tecnologias de informação e comunicações contribuem para a transformação da economia no sentido de colocar o conhecimento como o recurso mais estratégico e o aprendizado como o processo mais importante". Neste contexto, estratégias tradicionais, tais como produção em massa, conquista de ganho de escala e desenvolvimento de arquiteturas monolíticas que forcem a empresa a fazer tudo perdem eficácia (CHESBROUGH, 2003; SANCHEZ, 1999), assumindo relevância suas capacitações dinâmicas, ou seja, sua aptidão de adaptar-se ao ambiente pela reconfiguração de seus recursos (TEECE et al., 1997) e o seu capital intelectual (TEEECE, 2000). A está economia de contornos absolutamente ambíguos, e na qual a inovação tecnológica desempenha papel cada vez mais crítico, dá-se o nome neste artigo de Economia do Conhecimento (EC).

Embora haja um consenso de sua relevância na literatura, o conceito de inovação assume vários significados nas diferentes disciplinas que se debruçam sobre o tema atualmente. Grosso modo, inovar quer dizer introduzir algo novo ou renovar algo existente. Do ponto de vista da Teoria Administrativa, é importante entender que uma invenção não é necessariamente uma inovação, muito embora os dois fenômenos estejam relacionados (DOSI, 1982). Como afirma PLONSKY (2005), "inovação é a invenção que chega ao mercado" em condições competitivas. Segundo TEECE (1986), inovação tecnológica "...consists of certain technical knowledge about how to do things better than the existing state of the art". No contexto atual, a tecnologia depende não apenas das habilidades das mãos e dos olhos, do "aprender fazendo", envolvendo também conhecimentos técnicos formais ou científicos. Na inovação tecnológica baseada em ciência, cada vez mais relevante no novo paradigma tecnicoprodutivo, parte-se da articulação teórica sofisticada prévia ao desenvolvimento da tecnologia, que deve ser levada a cabo por profissionais com grande domínio das disciplinas científicas usadas nos negócios (CASSIOLATO, 1999). Na perspectiva dos economistas neoschumpeterianos, o conceito de inovação é ampliado, incorporando o de difusão pelo sistema econômico (FREEDMAN e SOETE, 1997). Vendo-a como um processo organizacional, a inovação tecnológica tem uma natureza sistêmica, que se revigora a partir das interações existentes entre as fases de pesquisa, desenvolvimento e difusão; da relação entre os diferentes departamentos internos à organização, tais como P\&D, marketing, operação e logística (CASSIOLATO e LASTRES, 2000); e da interação entre a firma e o ambiente externo (DOSI, 1982).

Pela criticidade do tema, FREEMAN e SOETE (1997) consideram que "deixar de inovar equivale a morrer" para a empresa contemporânea. Por conseguinte, a busca por inovações incrementais, identificadas como aquelas que procuram "fazer melhor o que já se fazia", ou por inovações radicais, consideradas aquelas capazes de criar novos mercados e produtos, tornou-se fundamental para a manutenção da competitividade das empresas no contexto da EC (CANONGIA et al., 2004; TIDD, BESSANT e PAVITT, 2005). Defendese que a importância atribuída por uma organização à questão da inovação está diretamente vinculada a sua cultura organizacional (PLONKY, 2005), o que é comunicado por meio dos valores e crenças que orientam sua estratégia corporativa (VASCONCELLOS, 2001; ZAGO, 2004). Dada a íntima relação entre inovação e estratégia, seria esquemático considerar a inovação apenas como uma função ou processo organizacional, 
sendo mais apropriado entender que a estratégia e a inovação "... são as duas faces de uma mesma moeda" (BURLAMAQUI e PROENÇA, 2003). Assim sendo, torna-se relevante explicitar o que se entende por estratégia neste estudo.

Conforme apontado pelo estudo de MINTZBERG et al. (2000), a revisão da literatura revela que a pesquisa e prática de estratégia apresentam diferenças de fundo epistemológico, se possa considerar que as diferentes correntes concordam que estratégia diz respeito à conquista e manutenção de uma vantagem competitiva (HAMEL e PRAHALAD, 1994; PORTER, 1980). Não cabe nos limites deste artigo entrar nesta discussão. Para o problema da pesquisa aqui retratada faz-se relevante superar o falso dilema estratégico "posicionamento versus visão baseada em recurso (RBV) em busca de modelos integrativos e dinâmicos. Este objetivo é parcialmente atingido pela articulação de dois arcabouços de trabalho: i) O modelo de capacitações dinâmicas de TEECE et al., (1997). Neste, o termo "capacitações" traduz o papel chave da estratégia de adaptar, integrar e reconfigurar habilidades e recursos e o adjetivo "dinâmicas" refere-se à capacidade de renovar competências em resposta às mudanças no ambiente; ii) O modelo integrativo de DAY e REIBSTEIN (1997). Aqui a estratégia é retratada como um processo retroalimentador, que tem como fontes da vantagem competitiva ativos e recursos superiores, que são usados para selecionar um posicionamento único no espaço produto-mercado. Dado que a dinâmica competitiva irá erodir as fontes da vantagem competitiva, a firma se vê forçada a renovar os seus investimentos em novos ativos e recursos superiores, recomeçando o ciclo de busca de rendas econômicas. É importante considerar por fim que, na configuração das suas estratégias competitivas, as firmas poderão ser forçadas a rever as formas de promoção do desenvolvimento tecnológico e as suas estruturas de gestão de $\mathrm{P} \& \mathrm{D}$ em busca de criatividade e tempestividade (CHESBROUGH, 2003).

\section{Ecossistemas de Inovação Tecnológica e Estruturas de Gestão de P\&D nas Empresas}

No passado, as firmas que tinham seus próprios centros profissionais de P\&D dispunham de um ativo estratégico que em muitos casos convertia-se em uma poderosa barreira à entrada de novos competidores (FREEMAN e SOETE, 1997). Há evidências históricas de que estes modelos fechados, com a presença de cientistas dedicados e regras rígidas de gestão, típicos da grande organização industrial integrada, auxiliaram empresas como DuPont e GE a conceber, desenvolver e comercializar inovações que foram determinantes para a competitividade delas no passado. No entanto, na medida em que cresceu o conteúdo tecnológico embutido nos produtos e processos, tornou-se praticamente impossível para uma empresa isolada deter todo o conhecimento do qual depende, bem como gerenciar o fluxo contínuo de inovações derivadas das diferentes trajetórias tecnológicas identificadas como críticas para a sua competitividade (CHAGAS JUNIOR, 2005). Ao mesmo tempo, há uma percepção de que o novo paradigma tecnoeconômico das TICs favoreceu a efetividade da instalação de redes de informação, envolvendo uma ampla gama de relações e tipos de interação com fornecedores e clientes (CASSIOLATO, 1999; CASTELLS, 1999). Adicionalmente, as arquiteturas modulares de produtos que se tornaram dominantes nos ramos diretamente associados ao novo paradigma estimularam fortemente os modelos em rede (SANCHEZ, 1999). Frente aos riscos de isolamento e ao caráter habilitador das TICs, a possibilidade de se acessarem informações críticas ou capacitações de parceiro é frequentemente citada como sendo uma das maiores motivações para a formação de redes estratégicas (PITASSI, 2004). Coerentes com os argumentos acima, pesquisadores defendem que os esforços de aprendizagem e inovação estão se deslocando para um processo exógeno, coletivo, multidirecional e em rede (CHESBROUGH, 2003).

Segundo TEIXEIRA e GUERRA (2002), uma rede de negócios é "marcada por uma forte especialização dos agentes que compõem suas cadeias de suprimentos, e uma intensa complementaridade entre eles, o que atenua 
ou elimina rivalidades potenciais". Um efeito esperado da complementaridade de competências produtivas, técnicas e organizacionais dos membros de uma rede de empresas é o estímulo à transformação em uma rede de aprendizado, entendida como um pool social de conhecimentos e informações que circulam entre seus membros. Estas redes geram fortes externalidades positivas, o que "confere a elas uma capacidade competitiva de adquirir, armazenar e renovar conhecimentos tácitos de uma forma muito mais dinâmica" (GOUSSEVSKAIA, 2005; VASCONCELOS, 2005). Se uma rede tem potencialmente o papel acima descrito, é fundamental que uma empresa compreenda que a inovação tecnológica não pode mais ser vista como um fato heroico, resultante do esforço isolado. Por conseguinte, o exame da efetividade de modelos que permitam a interação dinâmica da organização a um conjunto de instituições, incluindo empresas fornecedoras de equipamentos, clientes, institutos de pesquisa, governo, universidades e, no caso de inovações sistêmicas até competidores, passa a ser um aspecto chave de sua estratégia tecnológica (CAMPANÁRIO, 2002; CHAGAS JÚNIOR, 2005).

Analisando os casos de empresas geradas a partir do novo paradigma das TICs, CHESBROUGH (2003) sugere que Cisco, Lucent e Intel, entre outras, abriram mão de possuir estruturas fechadas e hierárquicas de P\&D em favor de modelos abertos e horizontais, o que as teria tornado mais permeáveis ao fluxo de conhecimentos e mais ágeis nos projetos de inovação tecnológica. Reconhecendo os riscos que as estruturas fechadas de $\mathrm{P} \& \mathrm{D}$ podem significar para a entrada de ideias inovadoras vindas de fora, empresas que outrora defendiam convictamente o modelo fechado também passaram a implantar novas estratégias de desenvolvimento tecnológico e de busca por novos mercados (Ibid, 2003). Diante deste quadro, a criação de sistemas ecológicos de inovação pode se converter em um mecanismo efetivo para acelerar a velocidade, infundir criatividade e gerar rendas adicionais na gestão de $\mathrm{P} \& \mathrm{D}$, oferecendo múltiplos padrões de captura e de uso das inovações tecnológicas ao nível da firma. Para obter os benefícios dos relacionamentos com parceiros, caberia então às empresas estabelecerem rotinas, processos e estruturas flexíveis, que viabilizem o acesso rápido e fácil dos participantes ao conhecimento tácito produzido na rede (Vasconcelos, 2005).

Na literatura estudada, não obstante reconhecer-se a necessidade de maior dinamismo e eficiência nos resultados dos projetos de P\&D (FREEMAN e SOETE, 1997), não há consenso quanto à emergência nas empresas de estruturas de gestão de P\&D mais adequadas aos desafios da EC. Argumenta-se que uma definição apriorística da estrutura de gestão da inovação que desconsidere o contexto institucional, o papel que os diferentes atores desempenham no processo e as regras de governança predominantes seriam inadequadas (PITASSI, 2004). Na visão de pesquisadores da área de gestão da cadeia de suprimentos, orientar processos de negócio, incluindo a inovação tecnológica, a partir das necessidades do cliente, favoreceria a adoção de estruturas virtuais na medida em que estas permitiriam às empresas ampliar o leque de respostas aos requisitos por meio da colaboração dinâmica e ágil com parceiros independentes (CHANDRASHEKAR e SCHARY, 1999). A vantagem deste modelo derivaria dos incentivos criados pelos mecanismos de mercado, tais como prêmios por produtividade, que acarretariam uma resposta mais rápida dos parceiros, quando comparada à resposta obtida nos relacionamentos estáveis, seguros e letárgicos que ocorrem usualmente na cadeia de suprimentos tradicionais (CHESBROUGH e TEECE, 1996). Nas estruturas virtuais, a oferta de proposições de valor independe do domínio interno das competências para construí-las (MOWSHOWITZ, 1997). Assumindo-se que o processo de produção de conhecimento torne-se mais complexo - e as tecnologias mais efêmeras - é razoável supor que a dinâmica dos relacionamentos da empresa favoreça formas virtuais de rede. Entende-se que a virtualidade potencializa a geração de inovações incrementais, uma vez que traz maior flexibilidade na busca das fontes de tecnologia que estarão embutidas nas próximas gerações de produtos e processos (PITASSI, 2004), reduzindo os riscos de aprisionamento aos ativos específicos a determinadas trajetórias tecnológicas (FREEMAN e SOETE, 1997). 


\section{O caso da Unidade de Negócio de Logística da Vale}

A Vale é a maior empresa privada do Brasil e a terceira maior empresa de mineração do mundo, com presença em 14 estados brasileiros e em cinco continentes. Líder mundial no mercado de minério de ferro e pelotas, a Vale também se destaca por gerenciar ativos de classe mundial que formam a base de um amplo e

integrado sistema multimodal, composto por uma malha ferroviária brasileira de cerca de $10.000 \mathrm{~km}$ de extensão, navios, terminais portuários e ferroviários e serviços rodoviários, por meio dos quais movimenta produtos próprios e de terceiros. Até o ano de 2006, a Logística era considerada a segunda unidade de negócios (UN) da Vale. Como tal, o planejamento estratégico do exercício de 2005 indicava que a UN deveria buscar agressivamente, além do crescimento nas operações de transporte e movimentação de carga, o aumento do portfólio de serviços por meio da oferta de soluções logísticas integradas. Geograficamente, as operações da Logística podem ser divididas em dois sistemas relativamente independentes: i) Norte, representado pela Estrada de Ferro de Carajás, a Ferrovia Norte-Sul e pelo Porto em São Luís; ii) Sul, composto pelas Estradas de Ferro Vitória a Minas, Ferrovia Centro Atlântica, Complexo Portuário de Tubarão, Terminal Marítimo Inácio Barbosa, e Porto Seco de Uberlândia. Além da malha terrestre, a Logística operava à época o serviço de cabotagem e feeder (navegação costeira) em diversos portos brasileiros, conforme exibido na Figura 1.

Figura 1

\section{Mapa de Atuação da Vale Logística}

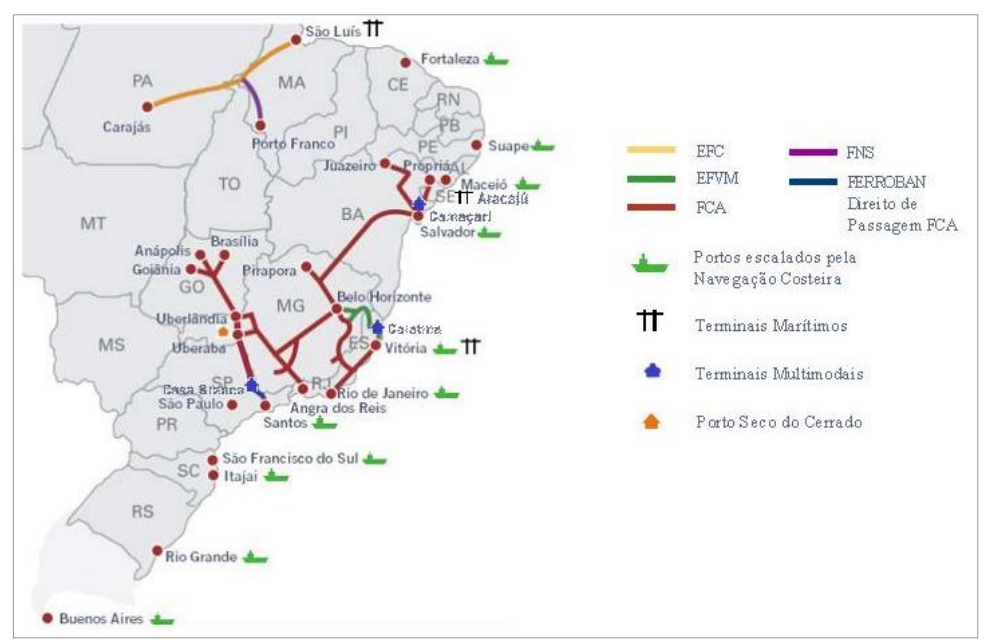

Fonte: Vale (www.vale.com, acesso dezembro de 2006)

Em 2008, os portos e terminais marítimos movimentaram 26.176 milhões de toneladas de carga geral e os serviços de logística geraram receita bruta de US\$ 1,6 bilhão, 5,3\% a mais do que em 2007. O transporte ferroviário de carga geral contribuiu com US\$ 1,3 bilhão, os serviços portuários com US\$ 255 milhões, a navegação de cabotagem e os serviços de transporte marítimo com US\$ 49 milhões. As ferrovias administradas pela empresa - Estrada de Ferro Carajás (EFC), Estrada de Ferro Vitória a Minas (EFVM), Ferrovia Centro-Atlântica (FCA) - transportaram 25,966 bilhões de toneladas quilômetro útil (tku) de carga geral para clientes.

\section{A Questão de P\&D na Vale}

A Vale destaca-se pela sua competência em pesquisas minerais. Graças em parte ao maior programa de pesquisa geológica já realizado no Brasil, a Companhia está hoje presente nos cinco continentes do globo 
terrestre. No que diz respeito à infraestrutura logística, a evolução tecnológica foi fundamental para apoiar o crescimento vertiginoso dos volumes movimentados nas últimas décadas. No desenvolvimento das ferrovias da Vale, a Estrada de Ferro Vitória a Minas (EFVM) e a Estrada de Ferro Carajás (EFC), consideradas referências mundiais no segmento de heavy-haul, o uso intensivo de tecnologias de campo e de bordo esteve sempre presente nas decisões de investimentos da empresa.

Apesar deste histórico de sucesso, em meados de 2003, a Diretoria Executiva da Vale identificou que, em função do crescimento da empresa, o processo de gestão da inovação tecnológica precisava ser revisto para acompanhar as mudanças organizacionais e os desafios estratégicos da internacionalização e da diversificação. As práticas de P\&D até a época, dado o tamanho da empresa, favoreciam a proliferação de projetos dispersos, sendo que o mesmo assunto era muitas vezes tratado em áreas diferentes sem que elas sequer soubessem. Por conseguinte, havia poucos mecanismos de disseminação de conhecimento, de aproveitamento de sinergias e de alavancagem dos recursos por meio de parcerias com outros centros de $\mathrm{P} \& \mathrm{D}$ externos e com as universidades. $\mathrm{O}$ ano de 2004 pode ser considerado um divisor de águas na gestão da tecnologia da Vale. Foi o primeiro ano do efetivo funcionamento do Comitê de Tecnologia da empresa. Pela primeira vez, todas as unidades de negócio foram convidadas a elaborar um Plano Diretor de Tecnologia (PDTec), os quais visavam, apoiando-se em uma metodologia padronizada, analisar o impacto da tecnologia na maximização do valor dos negócios da Vale e, a partir de regras claras de priorização, estabelecer um portfólio de projetos realmente efetivo. Coube também ao Comitê de Tecnologia a definição de tecnologias consideradas essenciais para a empresa como um todo, aplicadas em várias unidades de negócio, por isto também chamadas de Plataformas Tecnológicas, as quais deveriam ser objeto de fóruns de disseminação, compartilhamento de experiências e aprendizagem acelerada. Para liderar estes processos foram designadas diretorias sponsors. Um dos objetivos finais dos estudos realizados no âmbito do PDTec era a criação de um Centro de Tecnologia da Vale que assegurasse o atendimento das necessidades de inovação de cada UN e a captura das sinergias por ventura existentes.

\section{Modelo de Gestão Tecnológica na Logística}

Também na Logística o impacto do PDTec foi determinante para a construção do modelo de gestão da inovação tecnológica, cuja evolução é aqui retratada. Os principais resultados obtidos durante junho de 2004 e junho de 2005 foram (maiores detalhes destes resultados podem ser verificados em PITASSI e BARROS, 2005):

- Implantação de um modelo de gestão da inovação tecnológica que melhorou o alinhamento dinâmico às diretrizes refletidas na agenda estratégica da Vale Logística;

- Identificação de 210 projetos tecnológicos, os quais, após as devidas consolidações, eliminação de sobreposições e principalmente alinhamento às diretrizes estratégicas, resultaram em 69 projetos;

- Definição dos grupos tecnológicos e das tecnologias essenciais para a Vale Logística, o que permitiu a obtenção de uma tipologia orientadora para a definição do plano de capacitação tecnológica. Destacou-se entre estas tecnologias a pesquisa operacional;

- Definição de um posicionamento estratégico de seguidor rápido em acordo com a taxonomia de PAVITT (1990);

- Criação de uma estrutura voltada para o monitoramento da implantação dos projetos de tecnologia, o Escritório de Projetos da Logística (epLOG), que operacionalizou os mecanismos de governança na gestão tecnológica.

Durante o segundo semestre de 2005, tendo por objetivo evoluir o modelo de gestão tecnológica da Logística, membros da Gerência Geral responsável pela elaboração do PDTec da Logística fizeram visitas de benchmark às seguintes empresas: Cempes-Centro de Pesquisa da Petrobrás, Embraer, Embraco, CEMIG, Braskem, ALL 
logística, WEG e Siemens. As principais questões que nortearam as entrevistas semiestruturadas com os executivos de tecnologia das empresas visitadas foram:

- O que motivava uma empresa a optar por um centro tecnológico interno ou pela utilização de um instituto de tecnologia independente?

- O que definia o grau de centralização das estruturas de gestão de tecnologia em empresas diversificadas?

- Quando uma empresa deveria deixar a cargo das unidades de negócios as atividades de desenvolvimento, engenharia e plantas-piloto, ao invés de colocá-las sob a gestão de uma estrutura centralizada?

- Por que algumas empresas mantinham nos centros de pesquisa equipes cuja missão era apoiar as atividades de pós-venda?

- Por que algumas áreas se estruturavam por programas tecnológicos e qual a contribuição que estes traziam para a gestão de tecnologia?

- Em que nível e como as empresas estavam fazendo uso de programas de subvenção ou financiamento governamental?

- Como as empresas privadas estavam promovendo as pesquisas básicas e aplicadas relacionadas às trajetórias tecnológicas alvo?

- Como as empresas estavam construindo suas redes de inovação tecnológica e quais eram os parceiros que as compunham?

- O que motivava as empresas a buscarem um relacionamento preferencial com determinadas universidades-âncora?

- Como as empresas estavam promovendo a retenção dos especialistas e em que nível se encontrava o desenvolvimento das carreiras técnicas vinculadas às tecnologias chaves?

Tomando por base a consolidação dos resultados obtidos nas empresas visitadas, o referencial teórico adicional selecionado e a experiência adquirida pela equipe envolvida na 1a fase do PDTec da Logística, passos fundamentais foram dados em direção ao preenchimento de lacunas do modelo de gestão implantado até meados de 2005. As respostas individuais das empresas visitadas não foram evidenciadas neste artigo, dado o caráter confidencial destas informações. Outro fato relevante foi o diagnóstico das práticas de gestão de tecnologia em todas as áreas de negócio da CVRD preparado pelo Monitor Group, realizado em 2006, o qual evidenciou oportunidades relevantes, particularmente na gestão do pipeline de projetos de tecnologia.

\section{Alinhamento Estratégico - O Surgimento dos Programas Tecnológicos}

Uma das evidências mais importantes obtidas das visitas de benchamark foram os programas tecnológicos, ideia incluída na proposta de modelo de gestão. A estruturação de programas tecnológicos permitia enxergar com maior clareza a contribuição de um conjunto associado de tecnologias e competências tecnológicas para a estratégia do negócio. Por exemplo, o cálculo do valor presente líquido (VPL) dos investimentos tecnológicos ficaria muito mais consistente, quando realizado ao nível do programa e não mais de cada projeto individualmente, o que muitas vezes forçava uma discussão inócua sobre o quanto um projeto, dependente de outro, tinha contribuído para o alcance de uma meta que era, na verdade, resultado de vários projetos. A Figura 2 abaixo retrata o processo de estruturação dos programas. Cada um dos programas era constituído de um grupo de projetos, priorizados de acordo com critérios estabelecidos pelas demandas do negócio. Estes projetos foram distribuídos na linha do tempo, conforme as prioridades estabelecidas e as interdependências existentes, formando uma rota do desenvolvimento tecnológico pretendido. Para cada 
programa deveria haver um responsável definido pela Alta Administração e uma meta a ser alcançada no prazo de 5 a 10 anos. Também foram estabelecidos marcos de acompanhamento da evolução das metas dos programas com periodicidade que variavam entre três e seis meses, e na proposta apresentada defendia-se que os projetos que compunham cada programa deveriam constar da remuneração variável dos seus respectivos donos.

Figura 2

\section{Programas Tecnológicos}

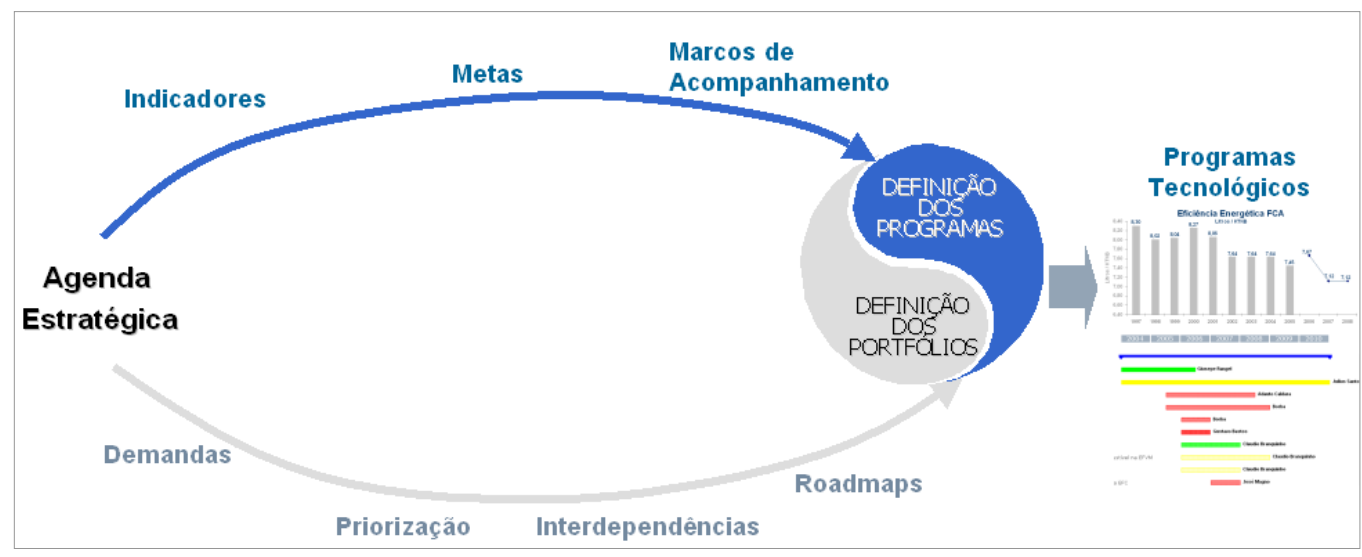

Fonte: PDTec Vale Logística - Proposta de Modelo de Gestão (documento interno)

\section{Gestão de Pipeline - A Evolução do Escritório de Projetos (epLOG)}

Ainda que a criação do epLOG em 2005 tenha trazido uma contribuição fundamental, o processo de monitoramento dos projetos tecnológicos carecia de uma visão mais abrangente e dinâmica, que correspondesse à estruturação dos Programas Tecnológicos. Na visão de pipeline, o processo para avaliar a entrada e saída de projetos, uma das grandes fragilidades do modelo anterior, ficaria mais consistente e visível. A metodologia proposta estava baseada na abordagem Stage-Gate de COOPER (2001), um roadmap conceitual e operacional que acompanha um projeto desde a ideia até a implantação. As fases são grupos de atividades paralelas realizadas por times multifuncionais e os gates são pontos de checagem do progresso dos projetos no pipeline, servindo para a equipe tomar decisões nas ações propostas em cada uma das fases. Antes de entrar no pipeline de um programa, a ideia, que poderia ser gerada internamente ou apresentada por um pesquisador externo ou fornecedor, deveria passar por alguns critérios de avaliação, tais como: alinhamento estratégico, valor para o negócio, probabilidade de sucesso e perda potencial evitada. A partir da avaliação do resultado da aplicação destes critérios, os projetos aprovados passariam a ser coordenados pelo epLOG. Acreditava-se que, desta forma, a gestão tecnológica ganharia um maior dinamismo, muito embora a disciplina exigida fosse vista pela equipe que elaborou a proposta de modelo de gestão como um grande desafio a ser superado.

\section{Gestão das Parcerias Tecnológicas}

No caso da UN de Logística Vale, a maior parte do desenvolvimento tecnológico era realizado nas áreas de engenharia e manutenção de vagões e locomotivas em parceria com entidades externas, o que se justificava principalmente: i) pelo fato dos projetos de inovação concentrarem-se na ponta final da cadeia de P\&D, em etapas menos complexas de adaptação das tecnologias aos requerimentos das áreas produtivas; ii) pela diversidade de trajetórias tecnológicas envolvidas no negócio e pela consequente ineficácia do esforço de domínio próprio de todas elas. Por exemplo, a área de logística da CVRD possuía em 2006 cerca de 20 patentes concedidas e outras $35 \mathrm{em}$ andamento, desenvolvidas em parte, por meio de parcerias com 
fornecedores. Ressalta-se que o resultado acima estava coerente com o posicionamento da UN de fast folower para grande parte das tecnologias embutidas nos serviços oferecidos e processos geridos (PITASSI e BARROS, 2005). Também é importante ressaltar que a logística é um serviço fortemente dependente das tecnologias de automação, compradas de grande fornecedores globais. Por conseguinte, o modelo sugerido e parcialmente adotado buscou ampliar a capacidade de monitorar a evolução das tecnologias existentes no mercado, adaptando-as, quando este fosse o caso, às necessidades do negócio. Este objetivo era normalmente alcançado por meio de contato com fornecedores, universidades, centros de pesquisa ou de empresas do mesmo segmento dispostas a vender suas tecnologias.

Nesta segunda fase do modelo de gestão tecnológica foi dada especial atenção à complementação da expertise e dos recursos internos da empresa por meio do estabelecimento de parcerias com universidades e institutos de P\&D externos. À época a UN mantinha convênios com as universidades federais de MG, RJ, ES, PA, MA, RGS, São Carlos e Viçosa. Além destas, estavam incluídas a PUC-Rio, INDG, MIT. Como exemplos de centros de P\&D se podem citar os Cetec e IPT (no Brasil), Fraunhofer (Alemanha), TTCi (Transportation Technology International Center, USA). Outros convênios foram negociados, tal como o termo de cooperação técnica entre a CVRD e a USP, que se tornou um marco do novo modelo de gestão de parcerias tecnológicas. Em dezembro de 2006, a equipe responsável pela construção do PDTEC da Vale Logística concluiu seus levantamentos e apresentou sua proposta, a qual envolvia os processos de gestão da inovação tecnológica e a estrutura organizacional, inclusive no que diz respeito à relação entre a área de P\&D da Logística e o Centro de Pesquisas da Vale, que seria criado mais à frente. Algumas das ações sugeridas no âmbito da Logística foram implantadas. Por exemplo, todos os contratos de pesquisa à época foram reavaliados, e, quando possível, as pesquisas foram canalizadas para as parcerias desenvolvidas pelo Centro Corporativo da Vale. No que se refere à área de $\mathrm{P} \& \mathrm{D}$ da Logística, a proposta aprovada pelos executivos defendia uma estrutura centralizada de gestão com a manutenção das atividades de desenvolvimento e engenharia nas áreas de negócio. Esta estrutura centralizada seria responsável por:

- Unificar a metodologia de gestão de projetos de P\&D adotada nas áreas da Logística e difundir melhores práticas;

- Avaliar sistematicamente o ambiente tecnológico e coordenar o processo de definição das rotas tecnológicas que seriam seguidas na UN de Logística da Vale;

- Gerenciar convênios com as Universidades e as parcerias tecnológicas com fornecedores;

- Coordenar a implantação da estratégia tecnológica em todas as áreas operacionais sob a gestão da UN (ferrovias, terminais de carga, portos e navegação);

- Coordenar a elaboração dos Planos Diretores de Tecnologia da Diretoria de Logística;

- Coordenar o núcleo de tecnologia do Escritório de Projetos da Logística (epLOG).

Um dos pontos da recomendação apresentada merece especial destaque: ainda que as características finais da estrutura de gestão de tecnologia da Vale como um todo não estivessem definidas, o diagnóstico no caso da UN de Logística defendia que uma estrutura virtual apresentava vantagens consideráveis quando comparada aos modelos tradicionais de áreas de P\&D levantadas nas pesquisas de campo. Por estrutura virtual de centro de pesquisa entendia-se um pequeno grupo de gestão, que atuasse como orquestrador e catalisador da interface entre as demandas dos clientes, as necessidades das áreas de engenharia interna e as competências aportadas por parceiros, fossem eles universidades, institutos de pesquisa ou fornecedores de equipamentos. Esta posição tinha como base lógica o seguinte pressuposto: na medida em que a mudança tecnológica se acelerasse, aprofundasse e espalhasse em nível global, formas tradicionais e rígidas de estruturas de P\&D tenderiam a perder sua efetividade. Neste cenário, importaria menos as características físicas do - e a durabilidade dos relacionamentos estabelecidos pelo - centro de pesquisa interno. Dado o posicionamento tecnológico pretendido, a amplitude das trajetórias tecnológicas dos negócios e a diversidade e a dinâmica de 
evolução das tecnologias-chave que suportavam a UN de Logística da Vale à época, entendeu-se que uma estrutura virtual traria mais flexibilidade na gestão dos relacionamentos e permitiria maior efetividade no acesso às fontes de conhecimentos, na medida em que estas fossem evoluindo.

No caso da Vale Logística, em função da natureza do seu negócio, os gestores entenderam que do ponto de vista da inovação tecnológica, seria importante a qualidade da rede de relacionamentos que a empresa estabelecesse com seus fornecedores inovadores, universidades de ponta, institutos de pesquisa e clientes espalhados ao redor do mundo. Para que a inovação tecnológica ocorresse de forma sistemática, sem riscos de esclerose nas fontes de inovação, a empresa deveria se afastar de formas rígidas de estrutura. Vale ressaltar que a condução da $\mathrm{P} \& \mathrm{D}$ poderia ser feita nas áreas de engenharia da própria empresa, em laboratórios de institutos independentes, nos sites das universidades ou em departamentos de P\&D de parceiros ou fornecedores. No que diz respeito ao grau de centralização das áreas de P\&D das diferentes áreas de negócio da Vale, a proposta defendia a criação de um centro de pesquisas único da Vale, que desempenharia um papel semelhante àquele que o Cenpes desempenhou para a Petrobrás e para a indústria de óleo e gás no Brasil e no mundo. A diferença entre os exemplos encontrados no campo convenceu os pesquisadores de que importava menos as especificidades da estrutura, e mais o entendimento correto do posicionamento tecnológico pretendido e a avaliação dos papéis que seriam desempenhados pelas diferentes organizações que compõem as redes de inovação tecnológica, particularmente os fornecedores inovadores.

\section{A Aceleração das Mudanças Estruturais na Vale e os Impactos no Modelo de Gestão de Tecnologia}

Vários acontecimentos ocorridos ao longo de 2007 e 2008 desencadearam profundas mudanças estruturais na Vale, com impactos diretos nas definições envolvendo o modelo de gestão de tecnologia. Destacam-se neste artigo alguns destes acontecimentos, procedendo-se a uma rápida análise da sua relação com a questão tecnológica na UN de Logística e na Vale. São eles: i) revisão das declarações de Missão e Visão da Vale no fim de 2006; ii) Compra da INCO; iii) Criação do Departamento de Automação; iv) a criação da Log-in, com o spin-off dos negócios de logística intermodal; v) criação da nova Diretoria Executiva de Tecnologia e Gestão Corporativa.

Antes que se discutam cada um dos pontos acima, é importante relembrar que o período retratado neste artigo, que vai de 2004 até o primeiro semestre de 2008, foi de intenso crescimento na atividade econômica no mundo comandado pelo crescimento da China, o que se refletia em uma preocupação recorrente com a possível falta de commodities em geral, e dos produtos comercializados pela Vale em particular. Este cenário levou a um aumento recursivo dos preços das commodities, ao crescimento sistemático do volume de minério de ferro exportado pela empresa e à busca do crescimento orgânico da Vale por meio de mega projetos, os quais permitiriam que a empresa auferisse benefícios de uma demanda que não dava sinais de arrefecimento e conquistasse e defendesse seu share de mercado. Os aumentos de volume transportado, cerca de 30 milhões de toneladas de minério de ferro em média por ano, representaram forte pressão sobre a infraestrutura instalada e sobre os processos operacionais das minas, ferrovias, portos e navios. Para agravar a situação, os diagnósticos realizados no âmbito do PDTec já haviam identificado lacunas nas camadas de infraestrutura elétrica, instrumentação e automação de processos, o que tenderia a se agravar com os aumentos previstos de volume. Para enfrentar esta situação foi criado o Departamento de Automação (DIAP), que centralizaria as iniciativas das áreas operacionais nestas tecnologias, convertendo-as em ferramentas efetivas para a maximização da confiabilidade operacional dos ativos da Vale, particularmente os ativos sob a gestão da Logística.

A mudança de declaração de Missão e Visão em fins de 2006, processo que foi coroado com a mudança de marca da empresa em 2007, fortaleceu o foco da empresa em mineração, ao mesmo tempo em que reforçava sua estratégia de diversificação neste segmento e sua imagem de empresa brasileira global e inovadora. Do ponto de vista da Logística, a área teve seu foco revisto, perdendo o status de UN, mas fortalecendo o seu 
papel original de suporte logístico às atividades core de mineração. A Visão deixava clara a intenção da empresa de se transformar na maior mineradora do mundo, reconhecida pela sua excelência operacional e na gestão de P\&D. Os valores traziam especial destaque para a questão da sustentabilidade. Coerente com a sua intenção de diversificar o portfólio de produtos e de tornar-se a maior mineradora do mundo, a Vale anunciou em outubro de 2006 a compra da canadense INCO, o que se traduziu na maior aquisição realizada por uma empresa brasileira até aquela data. A entrada da INCO, que marcou o início da globalização efetiva da empresa, trouxe urgência para a unificação dos processos transacionais e do sistema ERP. Do ponto de vista da gestão tecnológica, o processo de produção de Níquel traduziu-se em novas demandas e desafios para a Vale. Em fevereiro de 2007 a Vale comprou a australiana AMCI Holdings Austrália Pty (AMCI), que operava e controlava ativos de carvão, produto que passou a se constituir, junto com o níquel, o cobre e o alumínio, em um dos produtos com maior potencial de crescimento da empresa.

Com a revisão da missão da Vale, o negócio de Logística sofreu uma profunda reformulação interna que resultou, entre outras mudanças, no spin-off dos ativos envolvidos na movimentação de contêineres. Decorrente desta reestruturação foi criada a Log-In Logística Intermodal S.A., uma empresa independente focada no transporte e movimentação de cargas em contêineres e na prestação de soluções de logística integrada ao mercado. Reconhecendo potenciais conflitos que este negócio causava com as atividades core da empresa, a Vale defendeu que a criação Log-in permitiria um foco ainda maior no negócio principal e garantiria melhor qualidade dos serviços de logística e consequentemente maior retorno aos investimentos neste segmento. A saída dos ativos do negócio intermodal exigiu uma revisão de algumas rotas tecnológicas definidas no PDTec da Logística, particularmente naquelas que envolviam a TI e a pesquisa operacional. Em junho de 2007, a Vale criou uma nova Diretoria Executiva, encarregada pelas áreas de Tecnologia e Gestão Corporativa, trazendo para ocupar este posto o executivo Demian Fiocca, então presidente do BNDES. A alegação apresentada pela Alta Administração à época foi de que a criação desta Diretoria ajudaria no aperfeiçoamento do modelo de gestão, que estaria apoiado em sólida plataforma tecnológica que integraria as operações da Vale em todos os países onde a empresa passou a estar presente. Ficaram embaixo da nova estrutura os Departamentos de Automação, de Tecnologia da Informação e de Processos.

Em outubro de 2007, a Vale anunciou um ambicioso plano de investimentos que envolviam US\$ 59 bilhões os quais seriam gastos em cinco anos, sendo que destes, US\$ 11 bilhões seriam aplicados ainda em 2008. O plano também envolvia a geração de 60 mil novos empregos entre empregados diretos e contratados. Os ativos da Logística mereceram especial destaque e envolviam, entre outros projetos, a duplicação da EFC e do Terminal Portuário de Ponta da Madeira. As declarações dos executivos da Vale ao longo do segundo e terceiro trimestre de 2008, antevendo que o mercado de metais continuaria com uma demanda forte pelo menos até 2010, não deixavam dúvidas sobre o foco das preocupações da empresa: a implantação do programa de investimentos. Era natural que, dado o crescimento orgânico projetado, o que na prática significava duplicar a Vale em cinco anos, se fortalecesse ainda mais na empresa a importância da pesquisa geológica.

Também é importante destacar que o forte crescimento no "core business", associado à diversificação acelerada dos seus negócios, trouxe como resultado prático a criação ou a transferência de inúmeros Departamentos ao longo de 2006 e 2007. Cumpre lembrar, por fim que, ao longo de 2007 e 2008, a Vale viuse envolvida em fortes especulações sobre a aquisição de alguns dos seus principais concorrentes. O primeiro alvo foi a Alcan, empresa produtora de Alumínio, que foi posteriormente comprada pela BHP. O segundo boato envolvia a Anglo American, mineradora anglo-sul africana e um dos gigantes do setor. Pode-se argumentar que as iniciativas relatadas acima repercutiram na postergação de uma decisão final sobre o Centro de Tecnologia da Vale e sobre a implantação do modelo de gestão de tecnologia da Logística discutido neste artigo, muito embora passos significativos fossem dados no sentido de se aplicarem as recomendações levantadas ao longo dos anos de 2004 a 2006. 


\section{Conclusões}

O objetivo deste artigo era contribuir para o campo de estudo de gestão de C\&T nas empresas, relatando a evolução do processo de implantação de um modelo de gestão de tecnologia na unidade de negócios (UN) de Logística da Vale, particularmente a opção pela criação de uma estrutura virtual de gestão de tecnologia na UN. Por meio da discussão dos resultados pode-se assumir que o propósito da pesquisa foi atingido, pelo menos em grande parte. Destacam-se a seguir os principais aspectos da evolução do modelo de gestão na fase aqui retratada.

A primeira contribuição expressiva decorreu da estruturação dos programas tecnológicos. A visão de programas, ao invés de projetos tecnológicos isolados, mostrou-se uma forma mais apropriada de associar os objetivos estratégicos ao desenvolvimento tecnológico, com metas claras para o curto, médio e longo prazo. Ela também trouxe expressiva contribuição na simplificação aos cálculos do valor agregado pelos investimentos tecnológicos, ao permitir juntar projetos associados em torno de grandes temas. Destacam-se a seguir os programas tecnológicos em curso na época da conclusão do PDTec da Logística: Carga por Eixo; Comprimento dos Trens; Eficiência Energética; Excelência da Manutenção, Eficiência Operacional Portuária; Redução de Acidentes; Redução do Tempo em Pátios e Terminais e Redução do Impacto Ambiental.

Embora o contorno final do Centro de Tecnologia da Vale ainda estivesse por ser definido no final de 2008, houve avanços expressivos na estrutura de gestão de tecnologia da empresa e nas suas UNs nos últimos dois anos. Os estudos realizados no âmbito do PDTec entre os anos de 2005 e 2006 permitiram identificar lacunas e estimularam decisões que fortaleceram ainda mais o papel da tecnologia na empresa. Entre estas definições destacam-se: a criação do Departamento de Automação, responsável pela coordenação dos projetos de instrumentação e automação de processos operacionais; a criação da Diretoria Executiva de Tecnologia e Gestão, responsável pela consolidação dos processos de negócio da empresa e pela implantação de uma plataforma tecnológica global, com destaque para a implantação do ERP Oracle nas principais operações internacionais da empresa. Do ponto de vista da estrutura do centro de tecnologia, a discussão do estudo de caso destacou as potenciais vantagens de uma estrutura virtual na Logística, caracterizado por um pequeno grupo gestor que coordenasse os esforços de inovação: fortalecer o dinamismo na configuração das parcerias tecnológicas; permitir que a empresa se beneficiasse do potencial de inovação dos fornecedores de equipamentos, parte dos quais já possuía estruturas internas de $\mathrm{P} \& \mathrm{D}$, e dos institutos de pesquisa. Entende-se, no entanto, que no caso das empresas que por ventura adotem um posicionamento de inovator (PAVITT, 1990), a busca de breakthroughs tecnológicos poderá favorecer a opção por redes fechadas (PITASSI, 2004) ou estruturas de P\&D com instalações internas mais sofisticadas, ocupadas por pesquisadores contratados.

Por fim, entende-se que a discussão do caso demonstrou que a evolução do modelo pôde contribuir para a substancial melhora no processo de gestão estratégica da tecnologia na Logística e na Vale. Acredita-se que, tanto do ponto de vista acadêmico quanto do empresarial, a pesquisa ratificou a importância que a questão da inovação tecnológica está assumindo na gestão estratégica das organizações empresariais. A descrição do caso também trouxe evidências de que ganhe relevância nos modelos de gestão de $\mathrm{P} \& \mathrm{D}$ das empresas a preocupação com o uso de estruturas e modelos de governança que garantam a flexibilidade, a amplitude e a tempestividade que o tema da inovação está exigindo na Economia do Conhecimento. 


\section{Referências}

ARRUDA, Mauro, VELMUM, Roberto, HOLLANDA, Sandra. Inovação Tecnológica no Brasil: A Indústria em Busca da Competitividade Global. São Paulo: ANPEI, 2006.

BRITO CRUZ, Carlos H. A Universidade, a Empresa e a Pesquisa que o País Precisa. In: Castro Ana C. et al. (Org). Brasil em Desenvolvimento. São Paulo: Civilização Brasileira, 2005.

BURLAMAQUI, Leonardo, PROENÇA, Adriano. Inovação, Recursos e Comprometimento: em Direção a uma Teoria Estratégica da Firma. Revista Brasileira de Inovação, v.2, n.1, p.79-110, 2003.

CAMPANÁRIO, Milton de A. Tecnologia, Inovação e Sociedade. Apresentado no Seminário "Inovação Tecnológica, Economia e Sociedade", patrocinado pela Organización de Estados Iberoamericanos para la Educación, la Ciência y la Cultura. Setembro de 2002.

CANONGIA, C., et al. Foresight, Inteligência Competitiva e Gestão do Conhecimento: Instrumentos para a Gestão da Inovação. Revista Gestão \& Produção, v.11, n.2, p.231-238, 2004.

CASSIOLATO, José E. A Economia do Conhecimento e as Novas Políticas Industriais e Tecnológicas, cap.7. In LASTRES, Helena M.M.; ALBAGLI, Sarita. Informação e Globalização na Era do Conhecimento. Rio de Janeiro: Campus, 1999.

CASSIOLATO, José E. LASTRES, Helena M.M. Sistemas de Inovação: Políticas e Perspectivas. Parcerias Estratégicas, n.8, 2000.

CASTELLS, Manuel. A Sociedade em Rede. São Paulo: Editora Paz e Terra, 1999.

CHAGAS JUNIOR, Milton de F. A Evolução dos Modelos de Gestão do Processo de Inovação Tecnológica nas Firmas: O Caso da EMBRAER. 2005. Dissertação (Mestrado em Engenharia Aeronáutica e Mecânica) - Instituto Tecnológico de Aeronáutica, São José dos Campos, 2005.

CHANDRASHEKAR, Ashok; SCHARY, Philip B. Toward the Virtual Supply Chain: the convergence of IT and organization. The International Journal of Logistics Management, v.10, n.2, 1999.

CHECKLAND, P. B. From Framework through Experience to Learning: The Essential Nature of Action Research. In: Eds. Nissen, H., Klein, H. K. and Hirschheim, R. A. Information Systems Research: Contemporary Approaches and Emergent Traditions. Amsterdam: North-Holland, p.397-403, 1991.

CHESBROUGH, Henry W; TEECE, David J. When is Virtual Virtuous? Harvard Business Review, v.74, n.1, p.6573,1996 .

CHESBROUGH, Henry W. Open Innovation: The New Imperative for Creating and Profiting from Technology. Boston: Harvard Business Scholl Press, 2003.

COOPER, Robert G. Winning at New Products. Cambridge, Massachusetts: Perseus Books, 2001.DAY, George S.

DAY, George S.; SCHOEMAKER, Paul J. H. (Org.). Wharton on Managing Emerging Technologies. New York: John Wiley \& Sons, Inc., 2000.

DOSI, Giovanni. Technological Paradigms and Technological Trajectories. Research Policy, v.11, n.3, p.147-162, 1982.

FREEMAN, C. SOETE, Luc. The Economics of Industrial Innovation. 3. ed. London: Frances Pinter, 1997.

GOUSSEVSKAIA, Ana et al. Inovação Interativa: Capital Social, Knowledge Sharing Routines e Formação de Redes Interorganizacionais. Anais do $\mathbf{2 9}^{\circ}$ Encontro da ANPAD, Brasília, 2005. 
HAMEL, Gary, PRAHALAD, C.K. Competing for the Future. Boston: Harvard Business Scholl Press, 1994.

LUNDVALL, B. A. National Systems of Innovation: Towards a Theory of Innovation and Interactive Learning. London: Pinter Publishers, 1992.

MARTIN, Adriana; TORKOMIAN, Ana Lúcia. A Atividade de P\&D na Empresa: O Caso da Indústria Petroquímica. Polímeros, v.11, n.2, p.E4-E9. abr./jun. 2001.

MATIAS-PEREIRA, José; KRUGLIANSKAS, Isak. Gestão de inovação: a Lei de Inovação Tecnológica como Ferramenta de Apoio às Políticas Industrial e Tecnológica do Brasil. RAE Eletrônica, v.4, n.2, 2005.

MINTZBERG, Henry; AHLSTRAND, Bruce; LAMPEL, Joseph. Safari de Estratégia. Porto Alegre: Bookman, 2000.

MOWSHOWITZ, A. Virtual Organization. Communications of the ACM, v.40, n.9, p.30-38, 1997.

MUNIZ, S. Investimento Recente, Capacitação Tecnológica e Competitividade. São Paulo em Perspectiva, v.14, n.3, 2000 .

NELSON, R.R. and WINTER, S.G. An Evolutionary Theory of Economic Change. Cambridge: Harvard University Press, 1982.

PAVITT, K. What We Know About the Strategic Management of Technology. California Management Review, p. 17-96, Spring, 1990.

PITASSI, Claudio. Redes Estratégicas Virtuais: Uma Pesquisa Exploratória. 2004. Dissertação (Doutorado em Administração de Empresas) - Pontifícia Universidade Católica do Rio de Janeiro, Rio de Janeiro, 2004.

PITASSI, Claudio; BARROS, Maria A. Tecnologia e Gestão Estratégica: O caso da Vale Logística. Anais do 29 Encontro da ANPAD, Brasília, 2005.

PLONSKY, Guilherme A. Bases para um Movimento pela Inovação Tecnológica para o Brasil. São Paulo em Perspectiva. v.19 n.1, 2005.

PORTER, Michael E. Competitive Strategy: Techniques for Analyzing Industries and Competitors. New York: Free Press, 1980.

REIBSTEIN, David J (Org.). Wharton on Dynamic Competitive Strategy. New York: John Wiley \& Sons, Inc., 1997.

SANCHEZ, R. Modular Architectures in the Marketing Process. Journal of Marketing, v.63 (Special Issue), p.92-111, 1999.

SBRAGIA, Roberto; STAL, Eva. A Empresa e a Inovação Tecnológica: Motivações Parcerias e Papel do Estado. Fórum de Líderes Empresariais, novembro, n.11, p.6-14, 2004.

TEECE, D. Profiting from Technological Innovation: Implications for Integration, Collaboration, Licensing and Public Policy. Research Policy, v.15, n.6, p.285-305, 1986.

TEECE, D; PISANO, G; SHUEN. Dynamic Capabilities and Strategic Management. Strategic Management Journal, v.18, n.7, p.509-533, 1997.

TEECE, D. Managing Intellectual Capital. Oxford; Oxford University Press, 2000.

TEIXEIRA, F., GUERRA, O. Redes de Aprendizado em Sistemas Complexos de Produção. Revista de Administração de Empresas, São Paulo: FGV/SP, v.42. n.4, p.93-105, 2002.

TIDD, Joe, BESSANT, John, PAVITT, Keith. Managing Innovation: Integrating Technological, Market and Organizational Change, 3rd Edition Wext Sussex, UK: John Willey, 2005. 
VASCONCELLOS, Eduardo. Gerenciamento da Tecnologia: Um Instrumento para a Competitividade Empresarial. São Paulo: Editora Edgard Blucher, 2001.

VASCONCELOS, Maria C. R. L. Estratégia de Relacionamento entre os Membros da Cadeia Produtiva no Brasil: Reflexões sobre o Tema. Gestão \& Produção, v.12, n.3, p.393-404, set-dez. 2005.

YIN, Robert K. Case Study Research-Design and Methods. London: SAGE Publications, 1994.

ZAGO, C. et al. A Cultura Organizacional em uma Organização Pública: Aspectos Norteadores para o seu Gerenciamento. Anais do FENAPG-Encontro de Administração Pública e Governança. Rio de Janeiro, 2004. 